\title{
A Guerra Guaranítica num contexto de Cultura de Contato: uma interpretação sobre o caráter das interações entre guaranis missioneiros e sociedades ibéricas
}

\author{
The Guaranitic War in a Context of Contact Culture: an interpretation of the \\ character of interactions between guarani missionaries and iberian societies
}

Leandro Goya Fontella*

Instituto Federal Farroupilha (IFFar), Rio Grande do Sul (RS), Brasil

\begin{abstract}
RESUMO: Neste texto, a Guerra Guaranítica é examinada à luz da ferramenta conceitual do middle ground, formulada por Richard White. Busca-se averiguar alguns dos fatores elementares para a existência de uma zona de inteligibilidade comum entre as distintas sociedades em interação, com destaque para o frágil equilíbrio de forças entre elas. Esse exercício teórico foi realizado a partir da análise de relatos coevos e da interlocução com estudos amparados em sólidas bases empíricas, dos quais foi possível explorar as fontes transcritas e/ou os incidentes narrados e interpretados pelos autores. A título de conclusão, compreende-se que individualmente as sociedades ibéricas no Prata não reuniam condiçóes de subjugar os guaranis missioneiros envolvidos no conflito; que a temporária aliança bélica dos ibéricos promoveu uma ruptura efêmera do equilíbrio de poder na região, e que o modo como os integrantes de cada exército ibérico se comportaram com respeito aos códigos da cultura de contato condicionou as relações entre as frentes coloniais hispânica e portuguesa com os guaranis durante o restante do século XVIII.
\end{abstract}

PALAVRAS-CHAVE: Guerra Guaranítica. Missões Jesuítico-Guaranis. Middle Ground. Cultura de Contato. Interações Coloniais.

\footnotetext{
ABSTRACT: In this text, the Guaranitic War is examined in the light of the middle ground conceptual tool formulated by Richard White. We seek to investigate some of the elementary factors for the existence of a common intelligibility zone between the different interacting societies, highlighting the fragile balance of forces between them. This theoretical exercise was carried out based on the analysis of contemporary reports and the interlocution with studies based on solid empirical bases, from which it was possible to explore the sources transcribed and/or the incidents narrated and interpreted by the authors. By way of conclusion it can
}

* Professor do Instituto Federal Farroupilha (IFFar). Doutor em História Social pela Universidade Federal do Rio de Janeiro (PPGHiS-UFRJ). E-mail: leandro-goya@hotmail.com.

http://orcid.org/0000-0002-0276-3613. 
be understood that individually the Iberian societies in the Plata could not subjugate the missionary Guarani involved in the conflict; whereas the temporary war alliance of the Iberians has promoted an ephemeral rupture of the balance of power in the region, and; the manner in which the members of each Iberian army behaved with respect to the codes of contact culture conditioned the relations between the Spanish and Portuguese colonial fronts with the Guarani during the remainder of the eighteenth century.

KEYWORDS: Guaranitic War. Jesuit-Guarani Missions. Middle ground. Contact Culture. Colonial Interactions.

\section{Introdução}

A proposta deste texto é interpretar a Guerra Guaranítica por meio do arcabouço teórico do middle ground, elaborado por Richard White (2011 [1991]). ${ }^{1}$ Em estudo mais abrangente sobre o processo histórico das Missões Jesuítico-Guaranis do Paraguai, ao operar a sofisticada formulação conceitual desenvolvida por White, concluí que na região platina as interações entre sociedades indígenas e euro-americanas se pautavam nos termos daquilo que chamei de cultura de contato $^{2}$, isto é, uma zona de inteligibilidade mútua. Tal complexo relacional estabeleceu-se a partir da segunda metade do século XVII e extinguiu-se no decorrer das três primeiras décadas do século XIX, ensejando a reordenação social daquele espaço (FONTELLA, 2020 [no prelo]).

Para formular o argumento central da referida investigação, foi fundamental a interlocução com o trabalho de Guillermo Wilde (2009). A partir do prisma conceitual da etnogênese, esse autor concluiu que o guarani missioneiro foi o resultado de um processo de etnogênese missional. Para Wilde, o guarani missioneiro surgiu da homogeneização de uma população indígena diversificada através de um ordenamento espaço-temporal estabelecido por meio da vida nas reduções, do trabalho coletivo e dos preceitos cristãos. Nas palavras de Wilde, "[...] a tradição sociocultural das missões é o resultado de uma relação colonial em movimento, define um middle ground ou uma cultura criada no contato [...]" (2009, p. 37, grifos do autor). ${ }^{3}$ Assim, tal como percebeu Guillaume Boccara (2005), processos de mestiçagem e etnogênese podem provocar a emergência de um middle ground em determinados espaços.

A partir do argumento central de Wilde, assumi a premissa de que concomitantemente ao processo de etnogênese missional (durante os séculos XVII e XVIII) havia emergido uma cultura de contato na região platina. Assim sendo, busquei averiguar até que ponto se podia considerar que no Prata tinham se manifestado os fatores fundamentais verificados por Richard White para o desenvolvimento um middle ground na região dos Grandes Lagos norte-americanos. Para White, nesse espaço se estruturou uma zona de inteligibilidade mútua que pautou a convivência entre certos grupos indígenas e euro-americanos entre fins do século XVII e princípios do XIX. Concluí que, ao promover a estruturação do complexo reducional guaranítico como uma comunidade sociopolítica capaz de influenciar no equilíbrio de forças no Prata, o processo de etnogênese do guarani missioneiro viabilizou a emergência de uma cultura de contato. Esta, por sua vez, orientou as interaçôes entre as sociedades indígenas e euro-americanas de meados do século XVII até as primeiras décadas do XIX.

A Guerra Guaranítica configura-se num episódio privilegiado à análise de alguns dos elementos basilares para a existência de um espaço de significado comum entre distintas matrizes culturais, com destaque para o equilíbrio de poder entre elas e as condutas dos distintos agentes sociais em 
tempos de crise e confronto bélico. O conflito guaranítico constitui-se num tema recorrente na historiografia. ${ }^{4}$ Do imenso rol de estudos que examinam tal temática, optei por buscar respaldo em trabalhos amparados em sólidas bases empíricas, com os quais, além de dialogar, pude explorar as fontes transcritas e/ou os incidentes narrados e interpretados pelos autores (GARCIA, 2007; GOLIN, 1998; 2011; NEUMANN, 2005; PORTO, 1943; SILVEIRA, 1979; WILDE, 2009).

Os trabalhos de Porto e Silveira são narrativas descritivas detalhadas do conflito que, apesar de laudatórias das ações políticas e militares lusitanas, nos oferecem um repertório de documentos e relatos coevos reveladores dos incidentes da guerra. Por sua vez, Tau Golin, tendo como suporte documental sobretudo o Diário da expedição e demarcação da América Meridional e das Campanhas D’Missóes do rio Uruguay, de José Custódio de Sá e Faria, também elaborou uma minuciosa narrativa factual. Em virtude da riqueza dessa fonte, Golin desvelou novos aspectos do conflito. $\mathrm{O}$ autor enfatiza o caráter predatório do colonialismo ibérico frente ao que chama de experiência social alternativa desenvolvida nas missões jesuítico-guaranis.

A partir dos anos 2000, um importante número de estudos foi publicado sobre a referida temática. ${ }^{5}$ Estas pesquisas têm promovido uma interessante releitura desse episódio histórico. Por meio de um diálogo com a antropologia, tem-se prestado maior atenção ao universo simbólico e às estratégias indígenas. Desse universo, destaco os trabalhos de Eduardo Neumann (2005), Elisa Garcia (2007) e Guillermo Wilde (2009). Neumann concentra-se na utilização que os missioneiros fizeram das práticas letradas para estabelecer contato com as autoridades coloniais e expressar sua inconformidade com os termos do Tratado de Madri. Wilde defende que o parentesco e as práticas simbólicas indígenas tiveram papel fundamental na articulação política e mobilização militar dos guaranis missioneiros, possibilitando uma intensa conexão entre sujeitos que habitavam povos distintos. Garcia (2007) analisa como os guaranis manejavam estrategicamente a própria condição de ser índio no contexto do conflito.

Com base nesses estudos e em relatos coevos como os dos jesuítas Tadeo Henis e Juan de Escandón, este artigo assume um caráter de exercício teórico sobre a Guerra Guaranítica. Para isso, proponho-me a examinar o referido conflito operando a perspectiva conceitual do middle ground. A análise realizada não se encerra em si mesma, ela se incorpora a um esforço interpretativo mais amplo sobre o caráter das interaçôes entre sociedades indígenas e coloniais no Prata (FONTELLA, 2020 [no prelo]). O texto está organizado em duas seçôes. Na primeira, apresenta-se o conceito de middle ground e seus elementos constituidores. Na segunda seção, o processo e alguns eventos da Guerra Guaranítica são interpretados através da referida abordagem conceitual. Por fim, reserva-se um espaço às considerações finais.

\section{O middle ground e seus fatores fundamentais}

O livro The Middle Ground, nas palavras de seu autor, aborda a “[...] busca por acomodação e significado comum [de] como os europeus e os índios [...] construíram um mundo comum e mutuamente compreensível [onde] misturas criaram novos sistemas de significado e de troca" (WHITE, 2011, p. XXV-XXVI [1991]). Mas, White alerta que não se trata de acomodação no sentido de aculturação como um processo em que um grupo hegemônico impõe transformações a outro subjugado. O processo de mudanças culturais examinado por White ocorre no middle ground, que "[...] é o lugar entre: entre culturas, povos, e entre impérios e o mundo sem Estado 
das aldeias” (2011, p. XXVI [1991]). Nesse espaço, os atores sociais (indivíduos e/ou grupos) em interação "[...] ajustam suas diferenças através do que equivale a um processo de criativos e, muitas vezes oportunos, mal-entendidos” (WHITE, 2011, p. XXVI [1991]). Em meio as estas circunstâncias, sujeitos históricos com orientaçôes valorativas distintas buscavam "[...] persuadir os outros que são diferentes apelando para o que eles percebiam serem os valores e práticas daqueles outros” (WHITE, 2011, p. XXVI [1991]). Nesse contexto, com muita frequência, eles “[...] interpretaram mal e distorceram os valores e as práticas daqueles com quem lidavam, mas a partir desses mal-entendidos surgiram novos significados e através deles novas práticas - os significados compartilhados e práticas do middle ground” (WHITE, 2011, p. XXVI [1991]). Os processos de acomodaçóes davam-se em razão de que "[...] por longos períodos de tempo em grandes partes do mundo colonial [as sociedades euro-americanas] não podiam dominar aos índios nem ignorar eles” (WHITE, 2011, p. XXVI [1991]).

Isto posto, pode-se perceber que entre os elementos básicos que constituem o conceito de middle ground estão: acomodação de diferenças simbólicas, rejeição do conceito convencional de aculturação, processos de criativos mal-entendidos que geram novas convenções socioculturais, dependência mútua e frágil equilíbrio de forças entre os grupos sociais em interação.

Com base no cenário concreto do pays d'en haut, ${ }^{6}$ White refina sua elaboração teórica. Em sua avaliação, as condições de existência naquele espaço impeliam os povos algonquinos e os agentes coloniais franceses a "[...] se apoiar uns nos outros para alcançar fins bastante específicos" (WHITE, 2011, p. 51 [1991]); assim, "[...] eles tinham que chegar a alguma concepção comum de formas adequadas de agir; eles tiveram que criar o que eu já tenho referido como um middle ground" (WHITE, 2011, p. 50 [1991]). White argumenta que "[...] o middle ground dependia da incapacidade de ambos os lados de atingir seus fins através da força. $\mathrm{O}$ middle ground cresceu de acordo com a necessidade dos povos encontrarem meios, além da força, para obter a cooperação ou consentimento dos estrangeiros” (2011, p. 52 [1991]).

A região dos Grandes Lagos configurava-se num território cobiçado por dois impérios coloniais (o francês e o britânico) que não possuíam força suficiente para controlar a região sem a lealdade das sociedades indígenas que ali habitavam, as quais, por sua vez, também não tinham como simplesmente repelir e/ou interromper o avanço das sociedades euro-americanas. A ausência de uma força hegemônica entre os entes sociopolíticos em interação, talvez, seja a principal condição que fazia com que tais grupos buscassem afinar códigos consensuais que ensejassem uma coexistência minimamente estável. Em texto recente, White afirma:

[...] eu penso que fui bastante específico sobre os elementos que eram necessários para a construção de tal espaço: um confronto entre imperialismo ou regimes de Estados e formas não-estatais de organização social, um frágil equilibrio de poder, uma necessidade mútua ou um desejo pelo que o outro possui, e uma incapacidade de um lado reunir força o suficiente a compelir o outro a fazer o que desejava (2011, p. XII [1991], grifos nossos).

Nesse contexto, franceses e algonquinos erigiram um universo de convivência compartilhada, no qual

[...] aqueles que operavam no middle ground tinham necessidade de tentar compreender o mundo e o raciocínio dos outros e assimilar o suficiente desse raciocínio para colocá-lo em seus próprios propósitos. [...]. Talvez o aspecto central e definidor do middle ground fosse a vontade de quem o criou para justificar suas próprias açóes em termos do que eles perceberam ser as premissas culturais de seu parceiro (WHITE, 2011, p. 52 [1991], grifos nossos). 
A necessidade inevitável de comunicação nos termos de outrem gerou processos de oportunos e criativos mal-entendidos mútuos que produziam novos conteúdos culturais híbridos. Ao tornarem-se convençôes entre as distintas partes envolvidas, eles se transformavam num novo referencial que orientou as ações dos sujeitos históricos. Assim, à medida que os colonos, as autoridades e os comerciantes franceses se embrenharam no pays d'en haut, levaram consigo as práticas do middle ground como os chefes da aliança, a cerimônia calumet, a troca de presentes e os missionários católicos. Nessa perspectiva, o middle ground configura-se num "[...] conjunto de práticas, rituais, convençóes e crenças que embora constituídos por elementos dos grupos em contato é um todo separado das práticas e crenças de todos esses grupos” (WHITE, 2011, p. XIII [1991]).

Importa destacar também que White distingue o middle ground em duas dimensóes: a primeira é este como processo e a segunda como um espaço histórico em que o processo se converte no campo no qual se desenrolam as situaçóes de contato entre pessoas de distintas orientaçóes valorativas. Segundo White,

[...] o middle ground como um processo é bastante comum, já a construção de um espaço histórico em que o processo torna-se a base das relaçôes entre distintas pessoas é probabilisticamente menos comum. [...]. Há casos em que o processo pode ser evidente, mas o espaço pode não emergir. $\mathrm{O}$ espaço depende da criação de uma infraestrutura que possa suportar e expandir o processo, e essa infraestrutura era, [...], possível somente quando havia um frágil equilíbrio de poder e uma mútua necessidade entre as partes envolvidas (2006, p. 10, grifos nossos).

Outro ponto que merece atenção, pois pode gerar certa inconsistência conceitual, é a aparente similaridade entre as definições de fronteira e middle ground. Como o próprio autor colocou, o middle ground não ocorre em qualquer lugar. Mas, como notou Philip Deloria (2006), ele depende de uma condição fronteiriça para desenvolver-se, entretanto, nem toda fronteira transforma-se num middle ground. Em outras palavras, todo o middle ground é uma fronteira, mas nem toda a fronteira é um middle ground.

María Inés Moraes argumenta que a história colonial da região platina

[...] está atravessada pela interação [de] três fronteiras [uma jesuíta-guarani, a partir do noroeste; uma castelhana, a partir do sudoeste, e uma portuguesa, vindo do leste], cada uma respaldada por uma sociedade de caracteres específicos. A formação destes três eixos colonizadores implicou a formação de uma extensa zona de contato com os povos locais (MORAES, 2008, p. 29, grifos do autor). ${ }^{7}$

$\mathrm{O}$ middle ground como ferramenta teórica tem ensejado análises em outras regióes da América do Norte e para além dessa. Analisando as interações entre indígenas e os colonos no Vale do Arkansas (séc. XVII-XIX), Kathleen Duval (2004) defende que os colonos europeus não encontraram acomodação nem resistência, mas somente incorporação. Os índios definiram desde os padróes de uso da terra até fronteiras, enquanto os colonos europeus, situados distantes dos centros coloniais, viam-se dependentes de conexôes nativas e, portanto, eram impelidos a se inserir nos sistemas normativos e simbólicos nativos. Para a autora, apenas povos relativamente fracos desejavam o tipo de compromisso correspondente a um middle ground. 
O estudo de Alan Taylor (2006) diz respeito à política da terra entre índios iroqueses e sociedades coloniais em Nova York (1783-1800). O autor enfatiza como os iroqueses tentaram garantir partes de suas terras e soberania para continuar a viver de forma autônoma. $\mathrm{O}$ exame de Taylor coloca a política de terras no centro das negociaçóes interculturais e revela como a política imperialista dos EUA fez com que um universo compartilhado (middle ground) se transformasse em um mundo dividido.

$\mathrm{Na}$ coletânea The boundaries between us: natives and newcomers along the frontiers of the Old Northwest Territory, 1750-1850, organizada por Daniel P. Barr (2006), nove de onze ensaios dialogaram com The Middle Ground, circunstância que mostra a influência do estudo de White na historiografia sobre os povos nativos norte-americanos. No texto introdutório, Barr argumenta que o trabalho de White estabeleceu uma variável analítica em que os estudiosos passaram a ser obrigados a considerar, qual seja: o complexo mundo criado no contato entre sociedades indígenas e colonizadoras.

No prefácio da edição de vigésimo aniversário de publicação de seu livro, White aponta algumas pesquisas que operaram o conceito do middle ground. ${ }^{8}$ Avaliando o emprego que se tem feito do conceito, White afirma que se sente contente quando outros estudiosos fazem seu próprio uso original do mesmo, destacando aspectos que ele reconheceu, mas não se aprofundou. $\mathrm{O}$ autor acrescenta ainda que fica quase tão satisfeito quando os pesquisadores não conseguem encontrar um middle ground, como quando o encontram, pois, chegar a uma conclusão negativa também envolve um esforço para levar o conceito a sério (WHITE, 2011, p. XIV).

Entre aqueles que afirmam ter percebido o surgimento de um middle ground estão Claudia García (2007), Jonathan N. Lipman (2011) e James C. Scott (2009). Garcia empregou o conceito para analisar os índios miskitos do Caribe no fim do século XVII. Lipman, examinando as experiências históricas dos muçulmanos no noroeste da China, percebe a emergência de um espaço em que povos ajustam diferenças formulando convenções interculturais sem necessariamente percorrer a exata sequência das etapas ou depender de instituiçóes similares daquelas verificadas por White no pays d'en haut.

Scott (2009) foca seu estudo em Zomia, no sudeste asiático, que se caracteriza como uma zona de insubordinação, onde fragmentos de grupos maiores buscam refúgio e oportunidades além do alcance dos Estados ou conquistadores. Tais áreas serviram como abrigo ao longo de séculos para povos em fuga de projetos de Estados em formação e acabaram por compor uma vasta periferia resistente ao Estado. De modo assemelhando ao pays d'en haut, as identidades, em Zomia, são frequentemente plurais e os grupos locais são muitas vezes autônomos e facilmente fragmentados.

Henry Reynolds (2006) e Pekka Hämäläinen (2008) são dois exemplos de autores que empregaram o conceito, mas concluíram que nas regiões analisadas não emergiu um middle ground. Reynolds afirma, categoricamente, que na Austrália não se manifestou um middle ground. Por sua vez, embora não perceba a emergência de um middle ground nas áreas ocupadas pelo Império Comanche, Hämäläinen beneficia-se do conceito para refinar seu exame sobre a formação social na Comancheria.

White indica também os autores que em sua avaliação elaboraram as críticas mais contundentes ao seu estudo. Para ele, "[...] o principal ataque empírico [...] tem sido de Giles Havard, que, examinando o período inicial coberto pelo livro, afirma, com efeito, que não havia middle ground no pays d'en haut" (WHITE, 2011, p. XV, grifos do autor). Por outro lado, embora Havard também 
realize uma interessante crítica teórica, "[...] o mais forte ataque conceitual [...] tem vindo de James Merrell [...], mas ele só toca nas franjas dos pays d'en haut, e ele mal menciona The Middle Ground. Ele, no entanto, desafia a possibilidade de mediação bem-sucedida e a criação do mundo comum que eu descrevo" (WHITE, 2011, p. XV-XVI, grifos do autor). ${ }^{9}$

A amplitude dos estudos que utilizam o middle ground como referencial teórico demonstra o vigor analítico do conceito. Com efeito, vale enfatizar que o próprio White reconhece que pensou "[...] o middle ground como um processo que estava presente em outros lugares e outros tempos [...] [e que] as formas pelas quais os processos do middle ground produzem espaços equivalentes ao pays d'en haut não têm que seguir o modelo exato [descrito] em The Middle Ground, [...]. [Pois,] os melhores conceitos históricos são aqueles que são bons para pensar com [...]” (2011, p. XIII-XIV, grifos do autor).

Para analisar a Guerra Guaranítica empregando a ferramenta conceitual do middle ground, destaquei dois aspectos condicionantes e constituidores dele: a necessidade da vigência de um frágil equilíbrio de forças entre as sociedades que interagiam no Prata e o comportamento dos sujeitos históricos em tempos de crise e guerra.

\section{0 (des)equilíbrio de forças e o (des)respeito aos códigos da cultura de contato}

Em relação à América meridional, o Tratado de Madri (1750) buscava resolver os conflitos entre as Coroas ibéricas. $\mathrm{O}$ acordo definia que a Espanha teria controle exclusivo do rio da Prata. Para isso ser efetivado, os portugueses entregariam a Colônia do Sacramento aos espanhóis e em troca receberiam a regiáo dos Sete Povos Orientais do Rio Uruguai ao norte do rio Ibicuí e a leste do rio Uruguai, áreas contíguas aos territórios do Continente de São Pedro já ocupadas pelos lusitanos (GOLIN, 2011, p. 3). Com isso, cerca de 29 mil guaranis missioneiros que habitavam tal espaço deveriam migrar para oeste do rio Uruguai, levando seus bens móveis e semoventes, e fundar novas reduções. No plano simbólico, o tratado atentava contra um dos componentes formadores da identidade dos guaranis missioneiros, qual seja: a rivalidade com os lusitanos.

Contudo, entre os missioneiros, surgiu um movimento de insubordinação que englobava mais do que os sete povos afetados pelo tratado e que se confrontou militarmente com os reinos ibéricos. Esse conflito durou cerca de quatro anos, entre 1752 e 1756, e os embates militares concentraram-se em dois momentos. O primeiro em 1754, quando as forças ibéricas avançaram separadamente rumo aos Sete Povos e o segundo, em 1756, quando se reuniram e marcharam em conjunto (ver mapa em anexo).

Em agosto de 1753, o jesuíta Alonso Fernández enviou mensagem a Buenos Aires advertindo que “[...] não era possível convencer aos indígenas e [...] que era pouco aconselhável render armas a mais de 6000 indígenas que se juntariam dos seis povos aos 'infiéis' que haviam chamado para apoiá-los” (WILDE, 2009, p. 162-163, grifos do autor). Fernández referia-se a um fator decisivo para a obstinada disposição dos guaranis em manter a rebelião, a significativa força militar. Sabe-se que a formação das milícias missioneiras remonta aos embates com os paulistas na primeira metade do século XVII. Posteriormente, essas tropas de guaranis auxiliaram as forças espanholas em diversas ocasiões como nos cercos e assaltos à Colônia do Sacramento (AVELLANEDA; QUARLERI, 2007; NEUMANN, 2000; QUARLERI, 2008). 
A bem estruturada organização miliciana, amparada na robustez demográfica e econômica do complexo missioneiro, deu condiçôes para que os guaranis sustentassem um estado de guerra por cerca de três anos contra os impérios ibéricos. ${ }^{10}$ Ainda que somente em torno de um terço das reduções tenha se envolvido no conflito após a sua deflagração definitiva, os missioneiros conseguiram impor sérias dificuldades às investidas de espanhóis e portugueses até o desfecho em 1756.

Na primeira campanha, em 1754, saindo de Rio Grande, comandada por Gomes Freire, a coluna lusitana contava com “[...] mais de $1600^{11}$ soldados” (HENIS, 1836 [1754], parágrafo 42). Por outro lado, a força hispânica com cerca de 2.000 homens partiu de Buenos Aires liderados pelo governador José de Andonaegui (QUEVEDO, 1994, p. 16). Ainda naquele ano, em duas oportunidades, a frente espanhola bateu em retirada após confrontar-se com forças missioneiras. A primeira em maio, nos arredores de Yapejú, e a segunda em outubro, nas cercanias do rio Dayman (noroeste atual da República do Uruguai) quando as tropas espanholas debateram-se com uma força de cerca de “[...] 300 indígenas comandados pelo cacique yapejuano Rafael Paracatú [...]” (WILDE, 2009, p. 163).

As limitações da força militar hispânica no espaço platino devem ser compreendidas considerando o universo mais amplo da empresa colonial espanhola na América meridional. As forças bélicas na América espanhola eram formadas pelos Exército de Dotação, Exército de Reforço e as milícias. De acordo com Juan Marchena Fernández, nos anos 1750, em todo o espaço hispano-americano, as tropas regulares contavam com cerca de doze mil homens - dez mil no Exército de Dotação e dois mil no Exército de Reforço (1992a, p. 128). Na década de 1760, em pleno processo de reforma militar, o efetivo regular em Buenos Aires (que guarnecia quase todo o imenso espaço platino) oscilou entre 3.000 e 4.600 combatentes (FRADKIN, 2009, p. 91). Interpretando essas (e outras) informações, Raúl Fradkin argumenta que, em meados do Setecentos, as tropas regulares apresentavam muitas deficiências típicas dos modelos existentes, as quais se acentuavam pelas condiçôes logísticas, organizativas, sociais e culturais impostas pela situação colonial. Entre essas limitaçôes, destacam-se as dificuldades para se realizar grandes movimentos de tropas (2009, p. 80).

Em relação às milícias, Marchena Fernández defende que "[...] o estado geral das Milícias quando não das tropas veteranas [regulares] - era lamentável em quase todas as guarnições” (1992b, p. 80). Por sua vez, Fradkin afirma que, na região platina, as forças milicianas possuíam uma característica muito específica: a importância que as tropas guaranis desempenharam na composição de tais forças ao longo de boa parte do período colonial. Segundo o autor, frequentemente mobilizadas para defender Buenos Aires, Colônia do Sacramento ou Montevidéu, a robustez das milícias missioneiras provinha da capacidade jesuítica de organizar uma extensa estrutura miliciana que chegou a mobilizar em alguns momentos entre 3.000 e 7.000 homens (FRADKIN, 2009, p. 103).

Conforme o Padre jesuíta Tadeo Henis, as trinta reduçôes teriam "[...] 20.000 [guaranis] armados, (se todos os varóes pegassem as armas) [...]” (1836 [1754], parágrafo, 42). Provavelmente, Henis referia-se a todos os homens adultos ( 15 a 44 anos), mas obviamente que se tratava de um número superestimado, pois nem todos eles teriam condiçốes de se engajar nas atividades bélicas. Entretanto, mesmo se considerarmos que um terço dos homens adultos não pudesse ser mobilizado para o serviço das armas, o contingente militar dos trinta povos missioneiros poderia dispor de aproximadamente 13.300 guaranis, uma força guerreira expressiva para o contexto colonial americano.

Com base nessas informaçôes, pode-se depreender que as tropas espanholas no Prata não desfrutavam de vantagem significativa em relação ao contingente miliciano missioneiro em meados 
do Setecentos. Aqui o principal a notar não é somente o número de guaranis que efetivamente se engajaram no conflito guaranítico (significativamente menor do que a totalidade do contingente de guaranis adultos aptos a pegar em armas), mas na expressiva envergadura da força bélica do Complexo Reducional dos Trinta Povos. A simples existência de um potencial guerreiro de tal monta fazia com que as autoridades ibéricas, parte delas cientes das limitações de suas forças militares, receassem um enfrentamento com os missioneiros.

Analisando o contexto platino, Fradkin afirma que a partir da fundação da Colônia de Sacramento, em 1680, a beligerância fronteiriça operou uma crescente militarização da região. Do lado espanhol,

[...] as limitadas forças existentes deviam afrontar desafios de natureza muito diversa que impunham diferentes exigências: a defesa das localidades costeiras frente às ameaças de incursões marítimas de outras potências; a defesa da extensa fronteira 'seca' com os portugueses; a defesa das fronteiras com os índios não submetidos do chaco e das pampas, mas também com algumas tribos que se mantinham autônomas no mesmo litoral; a perseguição do crescente número de ladróes, bandidos e changadores; e também, deviam contribuir para reprimir as sublevações, como as ocorridas na área guaranítica em 1754 ou nos Andes em 1780 (2009, p. 79 , grifos do autor).

No que tange à defesa da fronteira com os grupos indígenas não submetidos, David J. Weber argumenta que os hispânicos enfrentavam enormes dificuldades em controlar outras sociedades indígenas como os araucanos, chiriguanos e pampas. Estas populaçóes lutaram para defender a base de seu sustento, transformando os locais mais periféricos dos assentamentos espanhóis em zonas que sofriam com frequentes incursóes de guerreiros nativos (WEBER, 2007, p. 110-111, p. 212; 227-234). Sobre isso, ainda nos primeiros momentos do conflito com os guaranis, os buenairenses tiveram que enfrentar um ataque de tribos indígenas não submetidas. Em seu diário sobre a Guerra Guaranítica, Tadeo Henis registrou que, em meados de 1754, "[...] toda a cidade de Buenos Aires padecia de uma grande seca; [e] que alguns milhares de índios do sul (chamam-se aucás, tueles e pueles), haviam vindo invadir a cidade” (1836 [1754], parágrafo, 42). Constantemente ocupados em se defender dos grupos indígenas insubmissos, em se confrontar com os portugueses e em enfrentar problemas de segurança interna, como o combate a criminosos, os colonos hispânicos no Prata possuíam pouca elasticidade para direcionar seus efetivos militares para outros fins, ainda mais quando estes envolviam grande, dispendiosa e prolongada mobilização de guerra. Nesse sentido, a Guerra Guaranítica, um confronto inesperado com uma população indígena considerada submetida, representava uma sobrecarga no aparato militar espanhol no espaço platino. Dessa perspectiva, os primeiros desdobramentos do conflito demonstram que, em relação aos guaranis, os espanhóis não detinham força guerreira consideravelmente superior e que, isoladamente, não possuíam condições para reprimir o levante guaranítico.

Quando em agosto de 1754 os espanhóis bateram em retirada, a coluna portuguesa estava estacionada nas cercanias do Rio Jacuí (centro do atual Estado brasileiro do Rio Grande do Sul). A dificuldade em ganhar terreno fez com que o destacamento português permanecesse em acampamentos improvisados por cerca de três meses. Segundo Henis, “[...] sofriam [...] não pouco os portugueses, de sorte que andavam [...] buscando brotos de palmas, e os despojos dos tigres, e ainda por estas mesmas coisas se matavam mutuamente os famintos, e se dizia que desse modo haviam perecido 69" (1836 [1754], parágrafo 56). 
As difíceis condiçôes descritas por Henis podem ser consideradas como um efeito das limitações que as estruturas militares portuguesas enfrentavam na América meridional. Segundo Adriano Comissoli, os efetivos militares ao sul da América lusitana eram "[...] quase sempre de soldados mal remunerados e de milicianos recrutados à força, os quais formavam grupos armados praticantes de guerrilhas e escaramuças, muito mais do que de grandes confrontos” (2011, p. 15). Nesse sentido, Paulo Possamai afirma que, por volta dos anos 1720, na guarnição militar da Colônia de Sacramento, o dia a dia dos recrutados era marcado por fortes tensóes em virtude da brutalidade com que eram tratados, dos constantes atrasos no soldo, da precariedade da distribuição de fardas e alimentos, assim como da dificuldade em receber um tratamento médico adequado. Um fluxo constante e intenso de deserção foi a principal consequência das adversidades vividas pelos militares portugueses no espaço platino (POSSAMAI, 2010, p. 30-31).

Nos três meses acampados nas margens do rio Jacuí, os soldados lusitanos conviveram com destacamentos de missioneiros. Se, por um lado, os guaranis hostilizavam os portugueses, por outro, parte deles aproximava-se do acampamento para dialogar, realizar trocas e comércio de artigos como erva-mate, sebo e charque (GARCIA, 2007, p. 45-46). O jesuíta Juan de Escandón relata que vários guaranis “[...] entravam no próprio mato e acampamento luso, como se estivessem em tempo de paz. Diziam então que queriam ver e falar ao General português, ou que estavam indo vender algumas coisas aos lusos ou deles comprar ainda outras” ([1760] 1983, p. 259). ${ }^{12}$ O sargento-mor lusitano, Luiz Manuel de Azevedo, também relatou que "[...] é inexplicável a prudência que o nosso General teve com os índios [...] tratando-os com muita caridade, mandando-lhes dar de vestir e comer, [vinham] fazer um pobríssimo negócio de bexigas de graxa de sabão, copos de chifre e outras bagatelas mais, [...]” (GARCIA, 2007, p. 47).

No acampamento, "Gomes Freire recebia pessoalmente os missioneiros e sempre os tratava bem. O exército estava também munido de presentes levados especialmente para ofertar aos índios, [...]. Além disso, os soldados portugueses também se ofereciam para casar com as filhas dos índios, [...]” (GARCIA, 2007, p. 46). Como demonstra Elisa Garcia (2007), as autoridades portuguesas buscavam desenvolver uma política de bom tratamento que visava a atrair os guaranis para a esfera de influência da Coroa lusitana, o que garantiria a efetiva ocupação do território dos Sete Povos pelos lusitanos.

Avalio que a necessidade de pôr em prática esse conjunto de ações para tratar com os índios demonstra que Portugal não possuía poder bélico para expulsar a população guarani da região e, tampouco, potencial demográfico para povoar o território. Por isso, as interações entre missioneiros e lusitanos eram multifacetadas. A situação de conflito não impediu que as autoridades portuguesas, por meio de uma série de atitudes, mostrassem para os guaranis que, após o fim da contenda, haveria a possibilidade deles se tornarem vassalos portugueses, permanecendo na região dos Sete Povos. A precariedade estrutural da sociedade portuguesa no Prata compôs o cenário de frágil equilíbrio de forças, sem o qual não teria sido possível a emergência de uma cultura de contato na região. Com efeito, aquele tipo de relacionamento com os guaranis (que prepostos lusitanos, como Gomes Freire, procuraram estabelecer) buscava observar os procedimentos e referenciais da cultura de contato vigente naquele espaço.

Após três meses de acampamento, ao tomar conhecimento do recuo da coluna hispânica e diante da incapacidade de seguir em marcha rumo às missóes, Gomes Freire celebrou unilateralmente um armistício com alguns caciques guaranis, por meio do qual se estabelecia o rio Jacuí como o limite entre as áreas portuguesas e missioneiras. Numa das cláusulas do tratado, estabelecia-se que: 
[...] se retirariam logo os caciques com os oficiais, e soldados a seus povos, e o exército português sem fazer-lhes dano, ou hostilidade alguma passaria o Rio Pardo, conservando-se de uma parte, e outra em inteira paz, até determinação dos dois soberanos, Fidelíssimo e Católico, ou bem até que o exército espanhol saia a campanha [...], se declara a divisão interina do rio de Viamão pelo Guaíba acima até aonde entra o Jacuí, que é esse em que nos achamos acampados, [...]. Ao que nessa divisão de rios fica da parte Norte não passará gado, ou índio algum, e sendo encontrados se poderá tomar o gado por perdido, e castigar os índios que forem achados; e da parte sul não passará português, e sendo achado algum será castigado pelos caciques, e demais justiças dos ditos Povos na mesma forma; exceto os que forem mandados com cartas de uma, ou outra parte, porque estes serão tratados com toda fidelidade (WILDE, 2009, p. 415 [nota 49]).

O acordo foi firmado por Gomes Freire e inúmeros chefes missioneiros, dentre os quais estavam "Cristóbal Acatú, Favián Guaquí, Francisco Antonio, Bartolomé Dandaú, Domingo Pindó, Ignacio Jauriguzú, Lorenzo Alpoypé y Alonso Guirayé” (WILDE, 2009, p. 415 [nota 49]). Creio que esse episódio se constitui numa evidência bastante reveladora no que diz respeito à paridade de forças entre lusitanos e missioneiros. Por si só, os atos de abrir negociações e de estabelecer uma trégua num contexto de guerra deflagrada indicam que, ao menos naquele momento específico, o comandante lusitano avaliava que não reunia condiçóes suficientes para, de modo isolado, suplantar a insurgência guarani.

Cessada a primeira campanha com as retiradas dos exércitos ibéricos em suas respectivas frentes, o ano de 1755 ficou marcado pela reorganização das tropas luso-hispânicas e a mudança de estratégia. Em virtude do fracasso das investidas individuais, acertou-se que portugueses e espanhóis se uniriam para uma marcha em conjunto para entrar nos Sete Povos (ver mapa em anexo). Em fins do dito ano, contando com 1.670 homens - dos quais 470 (30\%) militares regulares e 1.200 (70\%) milicianos a soldo (blandengues, gaudérios, malevas de campo, etc.), centenas deles patrocinados por latifundiários e comerciantes interessados no saque das Missóes -, o destacamento espanhol apresentou-se para a campanha. Por sua parte, os lusitanos reuniram um contingente de 1.606 soldados, 250 oficiais e 250 homens entre escravos destes últimos, particulares e comerciantes. O aparato bélico luso contava com 152 carretas; quatorze carros manchegos, para a palamenta e munições; três carros de pólvora; sete canhões de bronze, de calibre de duas libras, e três canhóezinhos de amiudar, de calibre um. Ademais, havia ainda mais duzentos mamelucos, de tradição bandeirante, recrutados em São Paulo, para marchar à frente, e duzentos minuanos para atuar na retaguarda (GOLIN, 2011, p. 10).

A união dos esforços de guerra ibéricos permitiu a montagem de uma expressiva força militar que ultrapassava o número de três mil combatentes, a qual em pouco tempo conseguiu sobrepujar as tropas missioneiras. ${ }^{13}$ Avalio que, com a confluência dos exércitos ibéricos, abriu-se um efêmero intervalo de tempo, durante o qual o equilíbrio de forças bélicas que vigorava na região foi afetado em desfavor da sociedade missioneira. Entretanto, esse desequilíbrio não tardaria a se desfazer. A aliança militar luso-hispânica tratava-se de uma resposta circunstancial a um problema ocasional, o qual incitou a coligação dos dois reinos rivais. Portanto, superado o empecilho criado pela insubordinação missioneira, Portugal e Espanha voltariam a campos opostos, retomando a normalidade e restaurando o equilíbrio de forças que endossava a cultura de contato estabelecida na região. A população guaranítica continuou numerosa e era cobiçada por ambos os impérios, as instituições políticas missioneiras e a organização miliciana foram preservadas, e o complexo 
produtivo seguiu bem estruturado. Logo, na sequência do século XVIII, mesmo com a derrota, os guaranis mantiveram-se como um componente significativo na relação de forças do espaço platino, o que, por sua vez, fez com que as interações entre ibéricos e guaranis seguissem sendo orientadas pela cultura de contato.

Após ingressarem nos Sete Povos, os contingentes espanhol e lusitano separaram-se, enquanto estes se alojaram na redução de Santo Ângelo, aqueles se estabeleceram em São João. Com base nos relatos do jesuíta Juan de Escandón, Elisa Garcia (2007) destacou as distintas atitudes tomadas por hispânicos e portugueses no trato com os indígenas ao longo do tempo em que ocuparam as reduçôes. Por volta de dez meses, o comandante português, Gomes Freire, permaneceu no território missioneiro e deu continuidade com a política de bem tratar os guaranis.

O primeiro aspecto levantado por Garcia refere-se ao butim de guerra. Conforme a autora, os espanhóis procederam de acordo com o costume e passaram a repartir os bens entre os soldados. Em contraste, Gomes Freire não só vetou a efetivação de tal prática como se preocupou em fazer isso de modo que sua benevolência repercutisse entre os missioneiros. De maneira quase solene, o comandante lusitano anunciou que "[...] em nome de seu Rei, no de seu próprio e no de todos os soldados lusos, [...] expressamente renunciava em favor dos infelizes índios a todos os bens móveis que lhe poderiam caber dos despojos daquele povo [...]" (ESCANDÓN, [1760] 1983, p. 349). Em outro trecho, fica registrado que o tratamento generoso dispensado aos guaranis:

[...] correram célebres como notícias pelos Povos, acompanhadas da compaixão, do carinho, agasalho e bons modos, com que os portugueses todos tratavam de maneira uniforme a todos os índios. Valia isso dos chefes, cabos e soldados, principalmente desde que, já aquartelados todos com o seu Gomes Freire em Santo Ângelo, os índios os viam não lhes fazendo nenhum vexame nem moléstia (ESCANDÓN, [1760] 1983, p. 350).

As manifestações de apreço dos portugueses para com os guaranis exprimiam-se também com os soldados se ofertando para casar com as mulheres missioneiras, no estabelecimento de um comércio justo com os indígenas, na indulgência de Gomes Freire com os delitos praticados pelos índios e na distinção e no respeito que ele dedicava aos caciques (GARCIA, 2007, p. 56, p. 59). Entretanto, a atitude de maior impacto foi o esforço empregado pelos lusitanos para convencer

[...] aos índios que não tinham intenção de fazer com que eles abandonassem a sua bela redução de Santo Ângelo, [...]. Essas notícias correram logo por todo o território missioneiro, impressionando profundamente os seus moradores o contraste entre o modo por que eram tratados pelos portugueses e o desprezo que sentiam dos espanhóis (PORTO, 1943, p. 415).

Para Elisa Garcia (2007), a discrepância entre as condutas hispânica e lusitana fez germinar entre os missioneiros um novo tipo de percepção sobre as distintas sociedades coloniais. O cenário pós-conflito colocava diante dos guaranis novos referenciais que passaram a ser comparados com os já existentes. Em primeiro, os missioneiros puderam realizar uma avaliação diacrônica, confrontando a noção histórica tradicional dos lusos, tido como cruéis inimigos, com a forma cordial com que estes vinham os tratando, e dos espanhóis e inacianos que até então eram considerados como aliados, mas que naquele momento os depreciavam e não prezavam por seus anseios (GARCIA, 2007, p. 55-59). 
De fato, as manifestações escritas feitas pelos guaranis durante o conflito dão indícios dessa mudança de perspectiva em relação aos espanhóis: em agosto de 1754, em uma missiva, os missioneiros de Conceição avisavam aos de Yapejú que "[...] chegaram nossos inimigos [...] estejamos prevenidos, porque são muitos os espanhóis que vêm [...]” (NEUMANN, 2005, p. 219). Em 1757, Hilario Yrama, alcaide de São Miguel, que vivia na estância desse povo, escreveu que "[...] por este nosso Passo de Ibucuy, por onde caminharam os espanhóis; os índios desconfiam dos espanhóis, nos dizem os 'pagãos'. Isso várias vezes o escutamos. Por isso nos apressamos em esconder a gente na Estância” (NEUMANN, 2005, p. 244, grifos do autor).

A essa altura dos acontecimentos, as relaçôes entre guaranis e espanhóis revelavam-se bastante ambíguas, isso, pois, os hispânicos, aliados de outrora, agora invadiam e pilhavam os povos, tratando os índios como inimigos. Todavia, como referido anteriormente, o exército espanhol não se compunha apenas por tropas formadas por soldados regulares que podiam ser mais facilmente controladas pelos oficiais, cerca de $70 \%$ eram de tropas milicianas animadas pela possibilidade de assaltar os bens missioneiros. Ademais, até aquele momento do período colonial, mediados pelos jesuítas, os contatos entre guaranis e sociedade hispano-americana eram tensos, uma vez que os colonos não dispunham de acesso à mão de obra guarani, tinham que competir com a produção missioneira nos mercados coloniais, por terras, gado e exploração dos ervais. Por isso, havia um rancor latente de ambos os lados, fato que explica em parte a postura ofensiva dos espanhóis para com os missioneiros.

Em segundo, os índios também estabeleceram comparação sincrônica, contrapondo a maneira benevolente dos portugueses e o modo indecoroso e avarento dos hispânicos. Por consequência, o imaginário guarani em relação aos ibéricos passou por uma considerável transformação, incorporando novos conceitos, em especial, no que diz respeito aos portugueses. Assim, alternativas como firmar uma aliança com os lusitanos para permanecer nos Povos sob a jurisdição do Rei Fidelíssimo, a qual poucos anos antes seria muito improvável, passou a figurar de modo mais sólido no horizonte de possibilidades dos guaranis (GARCIA, 2007, p. 55-59).

Em minha compreensão, os desdobramentos da estadia de Gomes Freire nas Missões reforçam o argumento da existência de uma cultura de contato na região missioneira (FONTELLA, 2020 [no prelo]). Ao longo de todo esse processo, Gomes Freire e seus comandados foram ganhando a confiança dos guaranis com ações que observavam os referenciais da cultura de contato. A cordialidade com que tratavam os índios, evitando ofensas e humilhações a estes, o tratamento justo nas relaçôes comerciais e a renúncia ao butim de guerra foram medidas habilmente manejadas pelos portugueses para se aproximar e interagir com os missioneiros. Para além desses procedimentos, Gomes Freire preocupou-se ainda em comunicar-se com os indígenas em guarani; distribuir-lhes regalos; estimular casamentos entre soldados portugueses e mulheres indígenas e respeitar rigorosamente a etiqueta política missioneira ao tratar com os caciques e cabildantes. Cabe-me enfatizar que não estou afirmando que os guaranis não se sentiam ultrajados e ressentidos em relação aos seus históricos inimigos, os portugueses. O que estou argumentando é que em circunstâncias em que os lusitanos podiam tomar ações abusivas e ainda mais ofensivas diante daqueles que percebiam como rebeldes vencidos, as atitudes amenas e respeitosas, conduzidas por Gomes Freire, consideravam os referenciais da cultura de contato, e abriram um novo campo de possibilidades até então inexistente para os guaranis serem vassalos do rei de Portugal. 
Esperavam-se essas condutas de aliados e não de povos considerados inimigos. Nesse sentido, os acontecimentos pós-conflito colocavam os missioneiros diante de certa perplexidade em função das expectativas que se tinha de quais deveriam ser os comportamentos assumidos por lusitanos e espanhóis. Por mais que houvesse um determinado grau de tensão entre hispânicos e guaranis, eles eram aliados históricos. Portanto, em uma situação conflituosa, os missioneiros esperavam que os laços de aliança deveriam servir de balizas para, ao menos, receberem um tratamento indulgente, justo e respeitoso por parte dos seus amigos de outrora. Obviamente que os missioneiros também possuíam a noção de que teriam que indenizar os vitoriosos, mas esperavam que essa matéria fosse definida por meio dos códigos da cultura de contato.

No entanto, os espanhóis dispensaram um tratamento hostil aos guaranis, pilhando os bens missioneiros, agindo de forma arbitrária no tocante ao comércio, infligindo insultos e humilhações aos índios, o que causava grande revolta e desconforto na população, principalmente, quando os constrangimentos eram dirigidos às lideranças políticas missioneiras. Richard White argumenta que no pays d'en haut os franceses se viam numa situação delicada quando precisavam punir chefes indígenas aliados. Uma pena muito rigorosa poderia ser encarada como um insulto desproporcional e acabaria agravando a situação, gerando grande revolta no grupo aliado que, por seu turno, não toleraria ver um de seus próceres ultrajado e envergonhado perante as outras sociedades nativas. A complexidade dessas circunstâncias era tanta que, muitas vezes, a solução para ela exigia maleabilidade, criatividade e muita prudência para impor uma punição que não provocasse uma humilhação desmedida aos líderes nativos. Nas palavras de White, esses processos “[...] revelam o substancial e crescente middle ground que os franco-algonquinos tinham criado. Aqui os problemas comuns podiam ser trabalhados e se chegar a soluções mutuamente compreensíveis” (WHITE, 2011 [1991], p. 90, grifos nossos).

$\mathrm{Na}$ resolução de tais impasses, algonquinos (que tomavam seu lugar de filhos) e franceses (que desempenhavam seu papel de pais) encenavam a estrutura patriarcal da aliança franco-algonquina. De acordo com os trâmites da cultura de contato, nos casos mais graves de delitos cometidos por lideranças indígenas, o governador exigia que elas aparecessem diante dele como penitentes pecadores aparecem diante do Deus cristão. Por outro lado, também focando sobre o patriarcado, mas de modo distinto, os índios buscavam congruência cultural para evitar uma punição muito rigorosa e obrigar as autoridades francesas a agir como pai benevolente (WHITE, 2011 [1991], p. 85).

No contexto missioneiro, segundo Hemetério José Velloso da Silveira, após a batalha de Caybaté,

[...] quando [os exércitos ibéricos] iam em marcha [rumo aos Sete Povos], chegou um índio de São Luiz com uma carta do reitor dizendo ter persuadido os indios de sua redução a obedecerem, confessar seu erro e implorar perdão. O chefe Andonaegui, [...], respondeu que, com palavras, não se acalmaria a cólera do rei (1979, p. 33 [grifos nossos]).

Dando-se crédito à narrativa de Silveira, pode-se perceber que ao menos parcela dos indígenas, através da mediação do padre da redução, procurou restabelecer seus vínculos com as autoridades coloniais e com o soberano espanhol, colocando-se na posição de filhos arrependidos dispostos a se reconciliar com seu pai. O comandante hispânico, porém, rechaçou um tratamento suave, alegando que as atitudes dos filhos haviam despertado a fúria do pai, a qual não seria dissipada com os pedidos de desculpas. 
O fator que complicava essa relação repousava no distanciamento histórico dos missioneiros com os colonos. Como já argumentei, até aquele instante da era colonial, os contatos entre missioneiros e sociedade colonial (e também com o rei da Espanha) eram intermediados pelos jesuítas, que blindavam os guaranis das demandas e investidas dos colonos, fazendo com que o complexo missioneiro desfrutasse de uma considerável autonomia política e econômica na região platina. Assim, a distância e a rivalidade mantida entre espanhóis e missioneiros faziam com que os homens mobilizados para submeter os índios pelas armas não estivessem comprometidos com a mediação e em desempenhar o papel de pai e, dessa forma, tratar os indígenas com benevolência. Nesse contexto, as autoridades hispânicas estavam mais comprometidas com os interesses dos colonos, os quais incluíam a pilhagem dos bens missioneiros, do que em agir como um pai benigno que acolhesse os missioneiros e reatasse os laços entre eles e o monarca.

A negligência dos colonos espanhóis com as disposiçóes da cultura de contato frustrava os compromissos do patriarcado hispânico. Por outro lado, Gomes Freire esforçava-se para desempenhar tal papel, abrindo a possibilidade para que os guaranis permanecessem na região dos Sete Povos e se tornassem vassalos do rei português. As diferentes posturas assumidas por espanhóis e portugueses não só refletiam suas interaçóes pretéritas com os missioneiros, mas também as ambições que possuíam naquele momento. Os hispânicos buscavam subjugar os guaranis rebeldes (condição que, aos seus olhos, dava-lhes o direito de pilhar os bens missioneiros) e, talvez, intensificar um processo de avanço de colonos sobre o espaço missioneiro. Por sua parte, os portugueses procuravam transformar sua imagem de inimigos para que os missioneiros os vissem como um aliado potencial, o que possibilitaria aos lusitanos efetivamente controlar a região dos Sete Povos Orientais. Ao interagirem com os missioneiros dentro das lógicas da cultura de contato e oferecerem a eles um renovado pacto paternalista com o Soberano português, os lusitanos acabaram alcançando um razoável êxito em sua tarefa de atrair os guaranis para a jurisdição lusitana. Estima-se que cerca de três mil missioneiros se deslocaram paulatinamente das Missóes para o Rio Grande de São Pedro, especialmente para a Fronteira do Rio Pardo, após a entrada das forças ibéricas nos Sete Povos Orientais (GARCIA, 2007; WILDE, 2009).

Com efeito, a forma como as forças militares ibéricas lidaram com os referenciais da cultura de contato acabou por exercer influência nas relações entre as frentes coloniais hispânica e portuguesa com os índios missioneiros durante o restante do século XVIII. Nesse sentido, enquanto os espanhóis mantiveram interaçóes com os guaranis num ambiente constantemente tenso, os lusitanos cada vez mais conseguiram se aproximar dos missioneiros até o ponto de, em 1801, convencerem as lideranças nativas dos Sete Povos Orientais a aliarem-se à Coroa portuguesa.

\section{Considerações finais}

O processo da Guerra Guaranítica expóe que, em meados do século XVIII, a região platina estava marcada por um frágil equilíbrio de forças entre as sociedades em interação, fator essencial para a existência de uma cultura de contato. A primeira fase do conflito evidencia que, isoladamente, tanto espanhóis quanto lusitanos careciam de força guerreira para reprimir o levante missioneiro, o qual contava com o envolvimento de menos de metade das trinta reduções. Ademais, a própria necessidade de reunir os exércitos ibéricos configura-se num importante indício de que nenhum dos grupos sociais da região tinha condições de exercer hegemonia sobre o espaço platino. 
A aliança ibérica fez com que, de modo breve, o equilíbrio de poder que vigorava na região pendesse em favor das sociedades coloniais. Todavia, assim que tal união se desfez, o frágil equilíbrio de forças restaurou-se e continuou dando esteio à cultura de contato. $O$ contingente populacional guaranítico manteve-se expressivo e cobiçado por ambas as Coroas; as instituições políticas missioneiras, a organização miliciana e o complexo produtivo seguiram estruturados ao menos até fins do século XVIII. Apesar da derrota, considerando todo o conjunto reducional, os guaranis permaneceram como um agente importante na relação de forças do espaço platino, condição que mantinha as interações entre missioneiros e as sociedades ibéricas pautadas na cultura de contato.

Referente ao comportamento que as forças ibéricas tiveram para com os missioneiros após ingressarem nos Sete Povos, a postura ofensiva dos espanhóis provocou ainda mais animosidade nos guaranis e refletia o histórico distanciamento e a rivalidade dos colonos com o complexo reducional. A histórica tensão dessa relação fez com que os espanhóis não estivessem comprometidos em restabelecer a relação patriarcal entre os missioneiros e o Rei hispânico, mas, sim, em subjugar rebeldes, condição que lhes dava o direito de pilhar os bens dos índios. Por seu turno, os missioneiros acreditavam que, como filhos de um mesmo pai, deveriam receber um tratamento benevolente por parte de seus irmãos e aliados. Nesse contexto, a indiferença dos colonos espanhóis com os códigos e as práticas da cultura de contato produziu um considerável abalo nos compromissos do patriarcado hispânico para com certa parcela dos missioneiros.

Por sua vez, as autoridades lusitanas buscaram, manejando os termos da cultura de contato, atrair os missioneiros para a influência e jurisdição portuguesa, prometendo que o Rei luso seria um pai mais justo, comprometido com o bem-estar dos guaranis e com a defesa de seus direitos. Ao longo do conflito, os agentes coloniais portugueses procuraram aproximar-se dos guaranis observando procedimentos da cultura de contato.

A observância ou o desprezo pelos referenciais da cultura de contato condicionava as relaçóes entre as frentes coloniais hispânica e portuguesa e os índios missioneiros. Em circunstâncias em que tais códigos fossem ignorados, os missioneiros podiam recorrer à intervenção moderadora do soberano espanhol que, como um Pai Protetor, deveria zelar pelos filhos e assegurar que seus direitos fossem respeitados. A solidez da relação patriarcal, no entanto, dependia da efetivação ou não dos compromissos assumidos, sobretudo, pelo Pai. Sendo assim, quando esse, por alguma razão, frustrava os acordos firmados, ele abria a possibilidade para a ocorrência de rearranjos no universo colonial. Nesse sentido, ao fim do confronto, a postura das forças espanholas acabou por provocar um sério abalo à relação patriarcal entre a Coroa hispânica e os missioneiros. Por outro lado, os portugueses colocavam diante dos guaranis uma alternativa de pacto político e relação patriarcal com o rei lusitano. Tais circunstâncias influenciaram e complexificaram ainda mais as interações entre ibéricos e missioneiros no restante do século XVIII.

\section{Referências}

ALDEN, D. The Treaty of Madrid (1750) and the Misions of Paraquaria. Workshop on: Jesuits and Intermediaries in the Early Modern World, 2001.

AVELLANEDA, Mercedes; QUARLERI, Lia. Las milicias guaraníes en el Paraguay y Río de la Plata: alcances y limitaciones (1649-1756). Estudos Ibero-Americanos, [s. I.], v. 33, n. 1, p. 109-132, 2007. 
AVILA, Arthur Lima De. Território contestado: a reescrita da história do oeste norte-americano: c.1985-c.1995. Porto Alegre: Editora da UFRGS, 2010.

AVILA, Arthur Lima De. Rememorando os Filhos de Onontio: Richard White, The Middle Ground e a escrita da história da América do Norte colonial. História (São Paulo), [s. I.], v. 30, n. 1, p. 264-286, 2011.

BARR, Daniel P. The boundaries between us: natives and newcomers along the frontiers of the Old Northwest Territory, 1750-1850. Kent, OH: The Kent State University Press, 2006.

BOCCARA, Guillaume. Mundos nuevos en las fronteras del Nuevo Mundo. Nuevo Mundo-Mundos Nuevos, [s. I.], 2005. Disponível em: <https://nuevomundo.revues.org/426>. Acesso em: 18 nov. 2019.

COMISSOLI, Adriano. Ajudado por homens que lhe obedecem de boa vontade: considerações sobre os laços de confiança entre comandantes e comandados nas forças militares luso-brasileiras no início do oitocentos. In: MUGGE, M; COMISSOLI, Adriano. Homens e Armas: recrutamento militar no Brasil século XIX. São Leopoldo: Oikos, 2011, p. 13-38.

DELORIA, Philip. What is the Middle Ground, Anyway? The William and Mary Quarterly, [s. I.], v. 63, n. 1, p. 15-22, 2006.

DESBARATS, C. Following “The Middle Ground”. The William and Mary Quarterly. v. 63, n. 1, p. 81-96, jan. 2006.

DUVAL, K. The Native Ground: Indians and Colonists in the Heart of the Continent. Philadelphia: University of Pennsylvania Press, 2004.

ESCANDÓN, Juan de. História da Transmigração dos Sete Povos Orientais. São Leopoldo: Instituto Anchietano de Pesquisas, [1760] 1983.

FONTELLA, L. G. As Missões Guaraníticas num contexto de cultura de contato: uma interpretação sobre as interações entre sociedades indígenas e euro-americanas (c.1730-c.1830). São Leopoldo: Oikos; Porto Alegre: ANPUH-RS, 2020 [no prelo].

FRADKIN, Raúl O. Tradiciones militares coloniales. El Río de la Plata antes de la revolución. In: HEINZ, Flávio M. (org.). Experiências nacionais, temas transversais: subsídios para uma história comparada da América Latina. São Leopoldo: Oikos, 2009. p. 74-126.

GANSON, B. The Guarani under the Spanish Rule in the Rio de la Plata. Stanford: Stanford University Press, 2003.

GARAVAGLIA, Juan Carlos. Un modo de producción subsidiario: la organización económica de las comunidades guaranízadas durante los siglos XVII-XVIII en la formación regional altoperuana-rioplatense. In: ASSODARIAN, C. S. et al. (eds.). Modos de Producción em America Latina. Mexico: Siglo Veintiuno, 1978.

GARAVAGLIA, Juan Carlos. Las misiones jesuíticas: Utopía y realidad. In: GARAVAGLIA, Juan Carlos (ed.). Economía, sociedad y regiones. Buenos Aires: Ediciones de la Flor, 1987. p. 120-191.

GARCÍA, Claudia. Ambivalencia de las representaciones coloniales: líderes indios y zambos de la Costa de Mosquitos a fines del Siglo XVIII. Revista de Indias, [S. I.], v. 67, n. 241, p. 673-694, 2007.

GARCIA, Elisa F. As Diversas Formas de Ser Índio: políticas indígenas e políticas indigenistas no Extremo Sul da América Portuguesa. PPGH/UFF, Rio de Janeiro, 2007.

GOLIN, Tau. A Guerra Guaranítica: como os exércitos de Portugal e Espanha destruíram os Sete Povos dos jesuítas e índios guaranis no Rio Grande do Sul (1750-1761). Passo Fundo: EdiUPF; Porto Alegre: Editora da UFRGS, 1998.

GOLIN, Tau. Cartografia da Guerra Guaranítica. Anais do 1o Simpósio Brasileiro de Cartografia Histórica, [s. I.], p. 1-16, 2011.

HÄMÄLÄINEN, Pekka. The Comanche Empire. New Haven CT: Yale University Press, 2008. E-book.

HAVARD, Giles. Empire et metissages: Indiens et Franfais dans le Pays d'en Haut, 1660-1775. Sillery, Quebec: Les Editions du Septentrion, 2003.

HENIS, P. Tadeo Xavier. “Diario Histórico de la Rebelión y Guerra de los Pueblos Guaraníes situados en la costa occidental del Rio Uruguay del año de 1754”. Buenos Aires: Imprenta del Estado, 1836 [1754]. Disponível em: <http://www.cervantesvirtual.com/obra-visor/diario-historico-de-la-rebelion-y-guerra-de-los-pueblosguaranis-situados-en-la-costa-oriental-del-rio-uruguay-del-ano-1754--0/html/ff99a966-82b1-11df-acc7002185ce6064_2.html\#I_0_>. Acesso em: 22 abr. 2020. 
JACKSON, Robert H. Missões nas fronteiras da América espanhola: análise comparativa. Estudos Ibero-Americanos, [s. I.], v. XXIX, n. 2, p. 51-78, 2003.

JACKSON, Robert H. The Post-Jesuit Expulsion Population of the Paraguay Missions, 1768-1803. Revista de História Regional, [s. I.], v. 13, n. 2, p. 134-169, 2008.

LIPMAN, Jonathan N. Familiar strangers: a history of Muslims in Northwest China. Washington: University Washington Press, 2011. E-book

MAEDER, Ernesto. Misiones del Paraguay: Conflicto y disolución de la sociedad guaraní (1768-1850). Madri: MAPFRE, 1992.

MAEDER, Ernesto. De las misiones del Paraguay a los estados nacionales. configuración y disolución de una región histórica: 1610-1810. In: GADELHA, Regina M. A. F. (ed.). Missões Guarani: impacto na sociedade contemporânea. São Paulo: Educ, 1999. p. 113-130.

MAEDER, Ernesto; BOLSI, Alfredo. La población de la provincia de Misiones en la época post-jesuítica. Folia Histórica del Nordeste, [s. I.], v. 5, p. 60-106, 1982.

MAEDER, Ernesto. Historiografía sobre las misiones jesuíticas de guaraníes. Evaluación del último quinqueño. Páginas sobre Hispanoamérica colonial. Sociedad y cultura, 1995. v. 2, p. 9-112.

MARCHENA FERNANDÉZ, J. Ejército y milicias en el mundo colonial americano. Madrid: MAPFRE, 1992a.

MARCHENA FERNANDÉZ, J. El Ejército de América y la descomposición del orden colonial. La otra mirada en un conflicto de lealtades. In: Militaria. Revista de cultura militar, n. 4, 1992b. p. 63-91

MELIÀ, B. S. J.; SAUL, M. V. De A.; MURARO, V. F. Bibliographie guarani. L'Ethnographie (numéro spécial-5 Centenaire de la découverte de l’Amérique. v. LXXXVIII, n. 111, p. 165-335, 1987.

MELIÀ, B. S. J.; NAGEL, L. M. Guaraníes y Jesuítas en tiempo de las Misiones: una bibliografía didáctica. Santo Ângelo: CEPAG-URI, 1995.

MELIÀ, B. S. J. La novedad guaraní (viejas cuestiones y nuevas preguntas). Revisita Bibliográfica (1987-2002). Revista de Indias, 2004. v. LXIV, n. 230, p. 175-226.

MERRELL, James. Into the American Woods: Negotiators on the Pennsylvania Frontier: New York: W.W. Norton, 1999.

MORAES, Maria Inés. La Pradera Perdida: Historia y economía del agro uruguayo: una visión de largo plazo 1760-1970. Montevideo: Linardi y Risso, 2008.

NEUMANN, Eduardo Santos. Fronteira e identidade: confrontos luso-guarani na Banda Oriental 1680-1757. Revista Complutense de História de América, [s. I.], v. 26, p. 73-92, 2000.

NEUMANN, Eduardo Santos. A fronteira tripartida: a formação do continente do Rio Grande - Século XVIII. In: GRIJÓ, Luiz Alberto; KÜHN, Fábio; GUAZELLI, Cesar Augusto Barcellos; NEUMANN, Eduardo Santos. (ed.). Capítulos de história do Rio Grande do Sul. Porto Alegre: Editora da UFRGS, 2004. p. 25-46.

NEUMANN, Eduardo S. Práticas letradas guaranis: produção e usos da escrita indígena (séculos XVII e XVIII). Rio de Janeiro: PPGHIS/UFRJ, 2005.

PORTO, Aurélio. História das Missões Orientais do Uruguai. Rio de Janeiro: Imprensa Nacional, 1943.

POSSAMAI, Paulo C. A guarnição da Colônia do Sacramento. In: POSSAMAI, Paulo C. Gente de guerra e fronteira: estudos de história militar do Rio Grande do Sul. Pelotas: Editora da UFPel, 2010. p. 13-32.

QUARLERI, Lia. Gobierno y liderazgo jesuítico-guaraní en tiempos de guerra (1752-1756). Revista de Indias, [s. I.], v. 68, n. 243, p. 89-114, 2008.

QUEVEDO, Júlio R. A Guerra Guaranítica: a rebelião colonial nas Missões. In: Estudos Ibero-Americanos. v. XX, n. 2, p. 5-26, dez. 1994.

REYNOLDS, Henry. The Other Side of the Frontier: Aboriginal Resistance to the European Invasion of Australia. Sydney: University of New South Wales Press, 2006. E-book.

SCOTT, James C. The art of not being governed. An anarchist History of upland Southeast Asia. New Haven CT: Yale University Press, 2009. E-book. 
SILVEIRA, José Hemetério Velloso da. As Missões Orientais e seus antigos domínios. Porto Alegre: Companhia União de Seguros Gerais, 1979.

TAYLOR, A. The Divided Ground: Indians, settlers, and the Northern Borderlands of the American Revolution. New York: Vintage Books, 2006.

WEBER, David J. Bárbaros: Ios españoles y sus salvajes en la era de la llustración. Barcelona: Editorial Crítica, 2007.

WHITE, Richard. Creative Misunderstandings and New Understanding. The William and Mary Quarterly, [s. I.], v. 63, n. 1, p. 9-14, 2006.

WHITE, Richard. The Middle Ground: Indians, Empires, and Republics in the Great Lakes Region, 1650-1815. New York (NY): Cambridge University Press, 2011.

WILDE, Guillermo. Religión y poder en las misiones de guaraníes. Buenos Aires: SB, 2009.

\section{Notas}

${ }^{1}$ Utilizo a edição comemorativa de vigésimo aniversário da publicação original que ocorreu em 1991.

${ }^{2}$ Formulei o termo cultura de contato como correspondente de middle ground. Elaborei esse termo em razão da expressão middle ground ser de difícil tradução literal para qualquer outro idioma no sentido definido por White. Segundo o próprio autor, "[...] porque o middle ground é uma metáfora espacial, o termo tem permitido uma confusão entre o processo de convenientes e criativos mal-entendidos e o espaço real que eu estava discutindo: o pays d'en haut ou o país superior do Canadá francês" (WHITE, 2011 [1991], p. XII, grifos do autor). Conforme argumenta Artur Lima de Avila, devido a essa ambivalência, “[...] o termo 'middle ground'é de difícil tradução, na medida em que aponta tanto para uma espacialidade, 'o território intermediário', quanto para uma condição mais geral, 'o meio-termo' entre partes conflitantes. [...] White parece tê-lo usado-o em ambos os sentidos [...]" (2010, p. 176 [nota 479], grifos do autor). Para adotar o termo cultura de contato, foi fundamental a interlocução com o estudo de Guillermo Wilde (2009) que compreende o universo sociocultural das missões guaraníticas como um middle ground, ou seja, uma cultura criada no contato através de interações coloniais móveis social e historicamente. Como meu interesse recai principalmente sobre o processo cultural de emergência de uma zona de inteligibilidade mútua, considerando a dificuldade de tradução do termo middle ground e o diálogo com os argumentos de Wilde, cunhei o termo cultura de contato. Ver Fontella (2020 [no prelo]).

${ }^{3} \mathrm{~A}$ fim de dar maior fluência ao texto, decidi redigi-lo quase que integralmente em língua portuguesa. Desse modo, todas as citações diretas de publicações em línguas estrangeiras constituem-se em traduções livres de minha autoria.

${ }^{4}$ Desde a década de 1980, foram organizadas algumas revisões bibliográfica sobre os estudos que tematizam os guaranis, ver: Ernesto Maeder (1995); Bartomeu S. J. Melià (2004); Bartomeu S. J. Melià; Marcos V. de Saul; Valmir F. Muraro (1987); Bartomeu S. J. Melià; Liane M. Nagel (1995).

${ }^{5}$ Destacam-se: Dauril Alden (2001), Barbara Ganson (2003), Elisa Garcia (2007), Eduardo Neumann (2005), Lia Quarleri (2008; 2009) e Guillermo Wilde (2009).

${ }^{6}$ De maneira esquemática, pode-se afirmar que essa região era “[...] delimitada a Leste pelo rio Ohio e pelo Lago Ontario, seguindo ao norte até as terras ao norte do Lago Superior, descendo pelo rio Mississipi, a oeste, até o rio Missouri, ao sul. Sua fronteira setentrional era o encontro deste curso d'água com o Ohio. Atualmente, o pays d'en haut corresponde à boa parte do Meio-Oeste norte-americano e ao Centro-Sul do Canadá" (AVILA, 2011, p. 282 [nota 13], grifos do autor).

${ }^{7}$ Analisando a formação do Continente de São Pedro no século XVIII, Eduardo Neumann (2004) elabora uma interpretação bastante semelhante a essa.

$8 \mathrm{Um}$ balanço sobre a influência de The middle ground na literatura estadunidense e canadense, seja empregando ou contestando seus argumentos, até o ano de 2006, foi realizado por Catherine Desbarats (2006).

${ }^{9}$ No referido prefácio, White refuta as críticas recebidas de Havard (2003) e Merrell (1999). Em virtude da dimensão exigida para este texto, não vou me estender nessa discussão.

${ }^{10}$ Sobre a estrutura demográfica das Missões Jesuítico-Guaranis, ver Jackson (2003; 2008); Maeder (1992; 1999); Maeder; Bolsi (1982). Em relação à economia do complexo reducional, ver Garavaglia $(1978 ; 1987)$.

${ }^{11}$ Os conteúdos dos documentos coevos em língua estrangeira foram traduzidos para o idioma português e adequados para a grafia e estrutura gramatical atuais. 
${ }^{12}$ Quando julguei necessário, ajustei a grafia e a gramática dos textos de fontes primárias redigidas em português ou já traduzidas para esse idioma.

${ }^{13}$ Importa destacar que a maioria dos povos ocidentais não se envolveu no conflito.

Recebido em: 07/01/2020

Aprovado em: 10/03/2020

\section{Anexo}

Mapa 1 - Campanhas da Guerra Guaranítica (1754 e 1756)

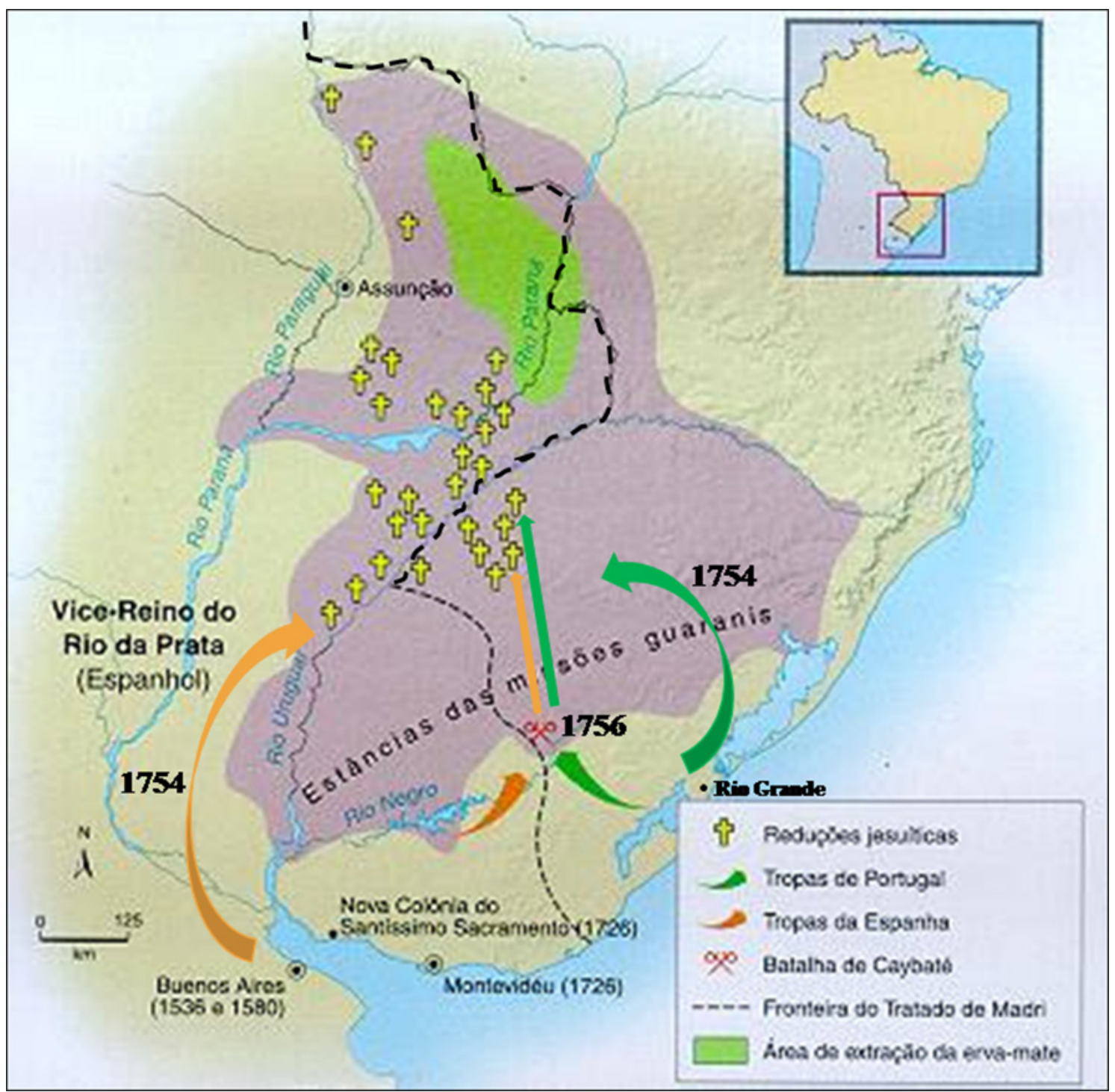

Fonte: Adaptação de imagem retirada de <http://noss2geografia.blogspot.com/2012/02/o-territoriolegalizado-os-tratados.html>. Acesso em: 24 abr. 2020. 